\title{
Chlamydia trachomatis, Ureaplasma urealyticum and Mycoplasma hominis urogenital infections in patients with infertility. Results from a large cross- sectional study.
}

\author{
Daniela Andrea Paira \\ CIBICI-CONICET. Facultad de Ciencias Químicas. Universidad Nacional de Córdoba. Argentina. \\ Guillermo Molina \\ Servicio de Urología y Andrología. Hospital Privado Universitario de Córdoba. Córdoba. Argentina. \\ Andrea Daniela Tissera \\ Laboratorio de Andrología y Reproducción (LAR). Córdoba. Argentina. \\ Carolina Olivera \\ CIBICI-CONICET. Facultad de Ciencias Químicas. Universidad Nacional de Córdoba. Argentina. \\ Rosa Isabel Molina \\ Laboratorio de Andrología y Reproducción (LAR). Córdoba. Argentina. \\ Ruben Dario Motrich ( $\square$ rmotrich@unc.edu.ar) \\ CIBICI-CONICET. Facultad de Ciencias Químicas. Universidad Nacional de Córdoba. Argentina.
}

\section{Research Article}

Keywords: Chlamydia trachomatis, Ureaplasma urealyticum, Mycoplasma hominis, infertility, infection, prevalence

Posted Date: February 19th, 2021

DOI: https://doi.org/10.21203/rs.3.rs-209613/v1

License: () (1) This work is licensed under a Creative Commons Attribution 4.0 International License. Read Full License 


\section{Abstract}

Female and male infertility have been associated to Chlamydia trachomatis, Ureaplasma urealyticum and Mycoplasma hominis urogenital infections. However, evidence from large studies assessing their prevalence and putative associations in patients with infertility is still needed. The study design was a cross-sectional study including 1554 female and 3610 male patients with infertility in Cordoba, Argentina. In women, the prevalence of $C$. trachomatis, $U$. urealyticum and $M$. hominis urogenital infection was $4.3 \%, 31.1 \%$ and $12.1 \%$ whereas in men it was $5.8 \%, 19.2 \%$ and $5.3 \%$, respectively. C. trachomatis infection was significantly more prevalent in men whereas $U$. urealyticum and $M$. hominis infections were more prevalent in women. Besides, $C$. trachomatis and $U$. urealyticum infections were significantly higher patients younger than 25 years. Moreover, $U$. urealyticum and $M$. hominis infections were associated to each other in either infertile women or men. Our data revealed that $C$. trachomatis, $U$. urealyticum and $M$. hominis are prevalent uropathogens in infertile patients. Of clinical importance, $C$. trachomatis and $U$. urealyticum infections were more prevalent in young patients whereas $U$. urealyticum and $M$. hominis are reciprocal risk factors of their co-infection. These results highlight the importance of including the screening of urogenital infections in the diagnostic workup of infertility.

\section{Introduction}

Urogenital infections are known causes of infertility ${ }^{1}$. Currently, infertility affects $15-20 \%$ of reproductive-aged couples worldwide and women and men equally contribute to infertility cases ${ }^{1,2}$. Sexually transmitted infections can impair fertility by different mechanisms: by directly damaging organs and gametes and/or, indirectly, by the induced inflammation and associated tissue damage, scarring and obstruction ${ }^{1,3}$. Moreover, infection-induced genital inflammation may alter the normal immunomodulation process that naturally occurs in the female genital tract after mating to facilitate fertilization, embryo implantation and promote embryo growth for a successful pregnancy ${ }^{4}$. Besides being the most frequent sexually transmitted bacterial infection worldwide, Chlamydia trachomatis is a common infection associated to infertility ${ }^{5}$. In women, $C$. trachomatis is a known cause of different urogenital pathologies such as acute urethritis, cervicitis and salpingitis that may lead to severe reproductive complications including pelvic inflammatory disease, chronic pelvic pain, ectopic pregnancy, miscarriage and tubal infertility ${ }^{6,7}$. In men, $C$. trachomatis is considered the most common agent of non-gonococcal urethritis and may cause epididymitis-orchitis, prostatitis, sperm tract obstructions and alterations in sperm quality ${ }^{8,9}$. On the other hand, Mycoplasma hominis and Ureaplasma urealyticum have also been recognized as sexually transmitted infections that could impair human fertility ${ }^{1}$. Although they are both known to colonize the female and male reproductive tracts as commensals, cumulative growing evidence has shown they are emerging sexually transmitted opportunistic pathogens able to cause asymptomatic chronic disorders affecting female and male fertility ${ }^{10-15}$. In men, U. urealyticum and $M$. hominis are causes of nongonococcal urethritis contaminating semen during ejaculation. Moreover, U. urealyticum has been proposed to cause prostatitis, epididymitis and infertility ${ }^{1}$. In addition, reported data have shown that both $U$. urealyticum and $M$. hominis could impair sperm quality ${ }^{11,16,17}$. In women, U. urealyticum and $M$. hominis may cause different pathologies including acute urethritis, bacterial vaginosis, pelvic inflammatory disease and tubal infertility $14,18,19$. Moreover, the asymptomatic colonization by mycoplasmas or ureaplasmas could induce pro-inflammatory immune responses in the endometrium that may impair pregnancy outcomes $2,9,14,20$.

The detection rates of $C$. trachomatis, $U$. urealyticum and $M$. hominis in the urogenital tract form infertile women and men has shown striking variations across regions and countries and in different groups when individuals were classified according to age, ethnicity and socioeconomic status $5,21-23$. In that regard, a growing number of studies have been reported during the last decade. However, compelling available data from large cross-sectional studies is scarce ${ }^{21-23}$. Moreover, reported data about the association of these infections in either infertile women or men is limited ${ }^{21-23}$. Since these infections may play a significant role in the etiology of infertility, we herein conducted a large observational investigation into urogenital $C$. trachomatis, $U$. urealyticum and $M$. hominis infections in infertile women and men seeking care for infertility. Moreover, we analyzed the associations among infections and with demographic parameters such as patient sex and age.

\section{Results}

Prevalence of $C$. trachomatis, U. urealyticum and M. hominis urogenital infection

A total of 5164 of infertile patients (1554 women and 3610 men) were enrolled in the study. The overall prevalence of urogenital $C$. trachomatis, $U$. urealyticum and $M$. hominis detection in the total population was $5.3 \%, 22.8 \%$ and $7.4 \%$, respectively (Table 1 ). Interestingly, U. urealyticum infection showed a remarkably higher overall prevalence than the others uropathogens analyzed. The prevalence of $C$. trachomatis infection was significantly higher in men than in women (5.8\% versus $4.3 \%, p=0.034$; Tables 1 and 2 ). Conversely, we found a significantly higher prevalence of both $U$. urealyticum and $M$. hominis infection in women (31.1 and 12.1, respectively) than in men (19.2 and 5.3\%, respectively) $(p<0.001$ and $p<0.001 ;$ Tables 1 and 2$)$.

Table 1. Prevalence of urogenital infections in infertile patients

\begin{tabular}{lccc}
\hline & Total & Women & Men \\
\hline & $(\mathrm{n}=5164)$ & $(\mathrm{n}=1554)$ & $(\mathrm{n}=3610)$ \\
\hline Chlamydia trachomatis, $n(\%)$ & $275(5.3 \%)$ & $67(4.3 \%)$ & $208(5.8 \%)$ \\
\hline Ureaplasma urealyticum, $n(\%)$ & $1176(22.8 \%)$ & $484(31.1 \%)$ & $692(19.2 \%)$ \\
Mycoplasma hominis, $n(\%)$ & $380(7.4 \%)$ & $88(12.1 \%)$ & $192(5.3 \%)$ \\
\hline
\end{tabular}


Table 2. Prevalence of infections in infertile patients according to sex and age

\begin{tabular}{|c|c|c|c|c|c|c|c|c|c|c|c|c|c|}
\hline \multicolumn{2}{|c|}{ Patients } & \multicolumn{4}{|c|}{ C. trachomatis infection } & \multicolumn{4}{|c|}{ U. urealyticum infection } & \multicolumn{4}{|c|}{ M. hominis infection } \\
\hline \multirow[b]{2}{*}{ Variables } & \multirow[b]{2}{*}{$\mathrm{n}$} & \multirow{2}{*}{$\begin{array}{l}\mathrm{n} \\
\text { (prevalence) }\end{array}$} & \multicolumn{3}{|c|}{$95 \%$} & \multirow[b]{2}{*}{$\mathrm{n}$ (prevalence) } & \multicolumn{3}{|c|}{$95 \%$} & \multirow[b]{2}{*}{$\mathrm{n}$ (prevalence) } & \multicolumn{3}{|c|}{$95 \%$} \\
\hline & & & Odds ratio & $\mathrm{CI}$ & $p$ & & Odds ratio & $\mathrm{CI}$ & & & Odds ratio & $\mathrm{CI}$ & $p$ \\
\hline \multicolumn{14}{|l|}{ Sex } \\
\hline Women & 1554 & $67(4.3 \%)$ & 1.00 (ref.) & & & $\begin{array}{r}484 \\
(31.1 \%)\end{array}$ & 1.00 (ref.) & & & $\begin{array}{c}188 \\
(12.1 \%)\end{array}$ & 1.00 (ref.) & & \\
\hline Men & 3610 & $208(5.8 \%)$ & 1.36 & 1.80 & $0.034 *$ & $692(19.2 \%)$ & 0.52 & $0.46-0.60$ & $<0.001 *$ & $192(5.3 \%)$ & 0.41 & & $3-0.50$ \\
\hline
\end{tabular}

\begin{tabular}{|c|c|c|c|c|c|c|c|c|c|c|c|c|c|c|c|}
\hline \multicolumn{16}{|l|}{ Age (y.o.) } \\
\hline \multicolumn{16}{|l|}{ Women } \\
\hline$>40$ & 35 & 17 (4.8\%) & & 1.00 (ref.) & & $107(30$ & & 1.00 (ref.) & & & \multicolumn{3}{|c|}{43 (12.1\%) } & & 1.00 (ref. \\
\hline $40-25$ & 1130 & 47 (4.2\%) & 0.94 & $\begin{array}{r}0.50- \\
1.78\end{array}$ & 0.847 & \multicolumn{3}{|c|}{341 (30.2\%) } & & 0.88 & $0.66-1$ & \multicolumn{2}{|r|}{0.372} & & \\
\hline$<25$ & 69 & $3(4.3 \%)$ & 0.96 & $\begin{array}{r}0.26- \\
3.50\end{array}$ & 0.949 & \multicolumn{3}{|c|}{$36(52.2 \%)$} & & 2.27 & $1.33-3$ & \multicolumn{3}{|c|}{$0.003^{*}$} & \\
\hline \multicolumn{16}{|l|}{ Men } \\
\hline$>40$ & 1356 & 88 (6.5\%) & \multicolumn{3}{|c|}{1.00 (ref.) } & \multicolumn{5}{|c|}{1.00 (ref.) } & & \multicolumn{4}{|r|}{$72(5.3$} \\
\hline $40-25$ & 2161 & 106 (4.9\%) & 0.71 & $0.52-0.95$ & $0.021 *$ & 433 (20.0\%) & 1.26 & $1.04-1.51$ & $0.016^{*}$ & & 116 (5.4\%) & 1.03 & $0.75-1.41$ & 0.863 & \\
\hline$<25$ & 93 & $14(15.1 \%)$ & 2.51 & $1.40-4.48$ & $0.002^{*}$ & 26 (28.0\%) & 1.66 & $1.04-2.66$ & $0.034^{*}$ & & $4(4.3 \%)$ & 0.72 & $0.26-2.02$ & 0.532 & \\
\hline
\end{tabular}

Univariate analysis. 95\%CI: 95\% confident interval. A*p<0.05 was considered statistically significant.

Associations among $C$. trachomatis, U. urealyticum and $M$. hominis urogenital infections

When assessing the co-infection between $C$. trachomatis and $U$. urealyticum, no significant association was found in either infertile women (OR: $1.62,95 \%$ Cl: $0.99-2.69, p \varangle 0.05$ ) or men (OR: $1.07,95 \% \mathrm{Cl}: 0.76-1.52, p \llbracket 0.05)$ (Figure $1 \mathrm{a}, \mathrm{d})$. In fact, a similar prevalence of $U$. urealyticum was found in $C$. trachomatis infected $(41.8 \%, 28 / 67)$ and $C$. trachomatis non-infected $(30.7 \%, 456 / 1487)$ women (Figure $1 \mathrm{a}$, Table 3$)$. In addition, a comparable prevalence of $U$. urealyticum were found in C. trachomatis infected $(20.2 \%, 42 / 208)$ and $C$. trachomatis non-infected $(19.1 \%, 650 / 3402)$ men (Figure 1d, Table 3).

Table 3. C. trachomatis, $U$. urealyticum and $M$. hominis co-infections in infertile patients

\begin{tabular}{|c|c|c|c|c|c|c|c|c|}
\hline & \multicolumn{4}{|c|}{ C. trachomatis } & \multicolumn{4}{|c|}{ M. hominis } \\
\hline & \multicolumn{2}{|c|}{ Women } & \multicolumn{2}{|c|}{ Men } & \multicolumn{2}{|c|}{ Women } & \multicolumn{2}{|c|}{ Men } \\
\hline & $\begin{array}{c}\text { Positive } \\
(\mathrm{n}=67)\end{array}$ & $\begin{array}{l}\text { Negative } \\
(\mathrm{n}=1487)\end{array}$ & $\begin{array}{l}\text { Positive } \\
(\mathrm{n}=208)\end{array}$ & $\begin{array}{l}\text { Negative } \\
(\mathrm{n}=3402)\end{array}$ & $\begin{array}{l}\text { Positive } \\
(\mathrm{n}=188)\end{array}$ & $\begin{array}{l}\text { Negative } \\
(\mathrm{n}=1366)\end{array}$ & $\begin{array}{l}\text { Positive } \\
(\mathrm{n}=192)\end{array}$ & $\begin{array}{l}\text { Negative } \\
(\mathrm{n}=3418)\end{array}$ \\
\hline \multicolumn{9}{|l|}{ U. urealyticum } \\
\hline Positive n (\%) & $28(41.8 \%)$ & $456(30.7 \%)$ & 42 (20.2\%) & 650 (19.1\%) & $171(90.9 \%) *$ & 313 (22.9\%) & $178(92.7 \%) *$ & $514(15.0 \%)$ \\
\hline Negative $\mathrm{n}(\%)$ & $39(58.2 \%)$ & 1031 (69.3\%) & $166(79.8 \%)$ & $2752(80.9 \%)$ & $17(9.1 \%)$ & $1053(77.1 \%)$ & $14(7.3 \%)$ & $2904(85.0 \%)$ \\
\hline \multicolumn{9}{|l|}{ M. hominis } \\
\hline Positive n (\%) & $12(17.9 \%)$ & $176(11.8 \%)$ & $14(6.7 \%)$ & $178(5.2 \%)$ & - & - & - & - \\
\hline Negative $\mathrm{n}(\%)$ & $55(82.1 \%)$ & 1311 (88.2\%) & $194(93.3 \%)$ & $3224(94.8 \%)$ & - & - & - & - \\
\hline
\end{tabular}

Univariate analysis. 95\%CI: 95\% confident interval. A *p<0.05 was considered statistically significant.

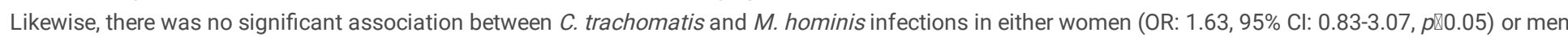

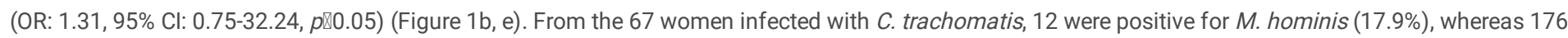

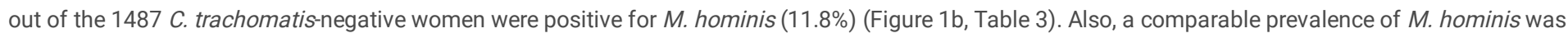
found in either $C$. trachomatis infected $(6.7 \%, 14 / 208)$ or $C$. trachomatis non-infected $(5.2 \%, 178 / 3402)$ men (Figure 1 e, Table 3$)$.

Interestingly, a significant association between M. hominis and U. urealyticum infection was found in women (OR: $33.84,95 \% \mathrm{Cl}: 20.25-56.86, p<0.0001)$ as well as in men (OR: 71.83, 95\% Cl: 41.89-187.10, p<0.0001) (Figure 1c, Table 3). As detailed in Table 3, from the 188 women positive for M. hominis, 171 (91.0\%) were positive for $U$. urealyticum. Similarly, a significantly increased prevalence of U. urealyticum (92.7\%) was found in M. hominis positive men (Figure 1f). In fact, from the 192 men positive for M. hominis detection, 178 (92.7\%) were positive for U. urealyticum (Table 3). Multivariate regression analysis further confirmed these tight associations, indicating that $U$. urealyticum and $M$. hominis act as mutual risk factors of infection either in women or men (Supplementary Table S1). 
Noteworthy, only $2.0 \%$ of infected women (11 out of 539 ) and $1.5 \%$ of infected men (13 out of 871 ) were co-infected with the three uropathogens analyzed (Supplementary Figure S1).

Demographic parameters associated to C. trachomatis, U. urealyticum and M. hominis infection

Remarkably, C. trachomatis, U. urealyticum and M. hominis infections were significantly associated with patient sex and age (Table 2). In fact, univariate regression analysis revealed that $C$. trachomatis infection was more likely to be detected in infertile men than in women with an odds ratio of 1.36 ( $95 \% \mathrm{Cl}$ : $1.02-1.80, p=0.034$ ) (Table 2). Moreover, a significant association was particularly found between $C$. trachomatis infection and men younger than 25 years (OR: 2.51, 95\% Cl: 1.40-4.48, p=0.002, Table 2) indicating that men, and especially those younger than 25 years, are at higher risk of infection than women (Table 2). Multivariate analysis further confirmed these associations (Supplementary Table S1).

On the contrary, $U$. urealyticum and $M$. hominis infections were associated to females, since men were less likely at risk of $U$. urealyticum and $M$. hominis infection than women with odds ratios of 0.52 (95\% IC: $0.46-0.60, \mathrm{p}<0.001$, Table 2) and 0.41 (95\% Cl: 0.33-0.50, p<0.001, Table 2), respectively. In addition, when analyzing the association of infection with patient sex and age, it was found that $U$. urealyticum was more prevalent in patients younger than 25 years, either in women or men (OR: 2.27, 95\% Cl: 1.33-3.89, $p=0.003$, and OR: 1.66, 95\% Cl: 1.04-2.66, $p=0.034$, respectively; Table 2). Multivariate analysis further confirmed these data (Supplementary Table S1).

These results indicate that $C$. trachomatis, $U$. urealyticum and $M$. hominis urogenital infections are associated with patient sex and age. In fact, individuals younger than 25 years at the highest risk of $C$. trachomatis and $U$. urealyticum infection. Moreover, our data show that men are at higher risk of $C$. trachomatis infection and, conversely, women are at higher risk of $U$. urealyticum and $M$. hominis infection.

\section{Discussion}

Chlamydia trachomatis, U. urealyticum and M. hominis are amongst the most frequent sexually transmitted bacterial infections. Moreover, they have been associated to infertility in either females or males ${ }^{1-3,10,22}$. Therefore, compelling data about the prevalence of urogenital $C$. trachomatis, $U$. urealyticum and $M$. hominis infection and their possible associations in infertile patients is of utmost importance. It has been shown that the prevalence of urogenital $C$. trachomatis infection in infertile men and women varies considerable across nations and regions and according to the subject population under study 24,25 . Besides, although a growing number of studies about the prevalence of urogenital $U$. urealyticum and $M$. hominis infections in infertile patients have been reported during the last decade, compelling available data from large cross-sectional studies of is still scarce ${ }^{21-23}$. Thus, we herein conducted a large observational investigation into urogenital $C$. trachomatis, $U$. urealyticum and $M$. hominis infections in women and men with infertility. Our data revealed a high overall prevalence of $C$. trachomatis, $U$. urealyticum and $M$. hominis infection in infertile patients. When analyzing data according to patient sex, the prevalence of $C$. trachomatis, $U$. urealyticum and $M$. hominis infection was $4.3 \%, 31.1 \%$ and $12.1 \%$ in infertile women, and $5.8 \%, 19.2 \%$ and $5.3 \%$ in infertile men, respectively. Univariate and multivariate regression analyses revealed that $C$. trachomatis infection was significantly more prevalent in infertile men whereas $U$. urealyticum and $M$. hominis infections were significantly more prevalent in infertile women. The higher prevalence of $C$. trachomatis urogenital infection we found in men with respect to women could be due to the fact that urogenital infections in men are much more frequently asymptomatic than in women ${ }^{8}$. Besides, our results are in line with recently reported data showing that the prevalence of $U$. urealyticum and $M$. hominis urogenital infections is higher in infertile women than in infertile men ${ }^{17}$. Furthermore, our results also showed that $C$. trachomatis and $U$. urealyticum infections were significantly more prevalent in young patients, particularly in those younger than 25 , indicating that age as a risk factor and in agreement with previously reported data 26,27. In fact, it is known that sexually transmitted infections are directly related to sexual experience, having young people more frequent sexual intercourses, less consistency of condom use and one or multiple sexual partners ${ }^{26,27}$. On the other hand, when assessing co-infections, only $2.0 \%$ of women and $1.5 \%$ of men were co-infected with the three uropathogens analyzed.

Our results support previously reported data. In a large observational study, Chen et al. found a prevalence of $C$. trachomatis infection of $3.5 \%$ in a population of 666 women seeking care for assisted reproduction in China, being significantly highest in patients younger than 25 years ${ }^{28}$. Moreover, Piscopo et al. reported a prevalence of $C$. trachomatis infection of $3.7 \%$ in women with tubal infertility in Brazil ${ }^{29}$. Besides and similar to our data, a prevalence of $C$. trachomatis infection of $4.3 \%$ in infertile men from Jordan has been reported ${ }^{30}$. Moreover, our results are in line with reported data by Sleha et al., who found a prevalence of $U$. urealyticum and $M$. hominis urogenital infection of $39.6 \%$ and $8.1 \%$, respectively, in Czech women undergoing an initial infertility evaluation

${ }^{31}$. In addition, Gdoura et al. found a prevalence of U. urealyticum and M. hominis of $15.4 \%$ and $9.6 \%$ in male partners from infertile couples from Tunisia ${ }^{32}$. Similar data were also reported in infertile men from China ${ }^{33}$.

However, significantly different prevalence rates of urogenital $C$. trachomatis, $U$. urealyticum or $M$. hominis infection in infertile women or men have been reported in other studies. In comparison with our data, a much lower prevalence of $U$. urealyticum infection was described in infertile men from Italy ${ }^{34}$. Similarly, Boeri et al. recently reported lower prevalences of $C$. trachomatis and $M$. hominis infection in Italian men with primary infertility ${ }^{35}$. Moreover, in a study conducted in infertile men from Spain, Veiga et al. found lower rates of $C$. trachomatis, U. urealyticum and $M$. hominis infection than ours $(0.9 \%, 15.1 \%$ and $0.9 \%$, respectively) ${ }^{6}$. In addition, considerably lower prevalence rates of $C$. trachomatis, $U$. urealyticum and $M$. hominis infection were reported in infertile women from the USA and Iran ${ }^{36,37}$. Several factors could underlie these differences such as disparities in population under study (geographical location, age, ethnicity, religion, socio-economic status, access to medical care, etc.) or study design (prospective versus retrospective, patient population size, methods used for diagnosis, etc.). However, our results are in line with cumulative reported data and supported by the large patient population analyzed, including 5164 infertile individuals (1554 women and 3610 men). 
Besides, our data revealed that $C$. trachomatis infection was not associated to either $U$. urealyticum or $M$. hominis in infertile women as well as in men. Conversely, and supporting recently reported data ${ }^{38-40}, U$. urealyticum or M. hominis were significantly associated to each other in either infertile women or men, indicating that $U$. urealyticum or $M$. hominis urogenital infection increased the risk of $M$. hominis or $U$. urealyticum co-infection. This tight infection association could be due to shared infection routes and/or pathophysiologic mechanisms ${ }^{1,10}$.

To our knowledge, this is the first cross-sectional study to investigate the prevalence and association of $C$. trachomatis, U. urealyticum and M. hominis in infertile women and men from Argentina. Being one of the few cross-sectional study performed in Latin American countries ${ }^{21,23}$ and the large number of patients analyzed are the main strengths of our study. However, our study has some limitations such as it did not include control groups of fertile women and men, in whom the prevalence of the infections under analysis could have been different from their infertile counterparts. Moreover, we did not have the information of the partner couple of every infertile women or men enrolled, which could have provided important information about infection concordance.

In conclusion, our results indicate that urogenital $C$. trachomatis, $U$. urealyticum and $M$. hominis infections are prevalent in infertile patients. $C$. trachomatis infection was significantly more prevalent in infertile men whereas $U$. urealyticum and $M$. hominis infections were more prevalent in infertile women. Of clinical importance, $C$. trachomatis and U. urealyticum infections were more prevalent in young patients, especially in those younger than 25 years. Moreover, $U$. urealyticum and $M$. hominis showed to be reciprocal risk factors of their co-infection in either infertile women or men. Overall, these results point out the importance to include the microbiological screening of urogenital infections in the diagnostic workup of infertility. Moreover, they highlight the need to reinforce preventive strategies at the primary healthcare level. Increasing awareness among people and health care practitioners are efficient approaches for the prevention of infection transmission. Future research is needed to unveil the true impacts of these uropathogens and the underlying pathophysiological mechanisms, which would allow the identification of proper and efficient treatments to more effectively reduce the burden of infertility.

\section{Methods}

Study design, patients and samples

This prospective, cross-sectional study was performed on a total cohort of 5164 patients (1554 females and 3610 males) seeking care for infertility at a joint Academic, Urology and Reproduction Health Center from Cordoba, Argentina, between January 2015 and November 2019. Inclusion criteria were female or male aged 18-60 years, not taking antibiotics when sampling or during the last 3 weeks, and with a recent diagnosis of infertility based on a thorough selfreported sexual and medical history ${ }^{41}$. Vaginal-swab and semen samples were collected from female and male patients, respectively. Vaginal swabs were collected by a dedicated operator who inserted Dacron swabs into the vagina up to the vault and rotated the swab in the vaginal vault. The specimens were immediately transferred to a tube containing cervical cell preservation solution and processed for analysis. Semen samples were collected by masturbation after 2-7 days of sexual abstinence and processed within $1 \mathrm{~h}$ of collection.

\section{Ethical approval}

The study was carried out in accordance with The Code of Ethics of the World Medical Association (Declaration of Helsinki) standards and the Argentinian legislation for protection of personal data (Law 25326). The experimental protocol was approved by the Institutional Ethics Committee from the Hospital Nacional de Clinicas, Universidad Nacional de Cordoba (RePIS \#3512). All patients provided a signed written informed consent form agreeing to share their own anonymous information prior to enrollment.

DNA extraction and C. trachomatis detection

Total DNA was extracted from vaginal or semen samples and C. trachomatis infection detected by polymerase chain reaction (PCR) using the Chlamydia trachomatis 330/740 IC PCR kit (Sacace Biotechnologies Srl, Como, Italy) and within $4 \mathrm{~h}$ of sample collection.

\section{$M$. hominis and $U$. urealyticum detection}

M. hominis or U. urealyticum infections were assessed by culture using the commercially available colorimetric kit Mycofast RevolutioN (ELITech Group, Puteaux, France). Briefly, $100 \mu \mathrm{l}$ of vaginal swab seeded transport medium or semen were added to the $M$. hominis and U. urealyticum wells, sealed and incubated at $37^{\circ} \mathrm{C} \pm 1^{\circ} \mathrm{C}$ for $24 \mathrm{~h}$. After incubation, orange or red color changes indicated the presence of $M$. hominis and/or $U$. urealyticum, respectively.

\section{Statistics}

Demographic characteristics (age, sex) and co-infections were compared between infected and non-infected patients using the chi-square test and the odds ratios (OR) and $95 \%$ confidence intervals (Cl) were calculated. Univariate and multivariate logistic regression analyses for all variables were performed to determine associations or risk factors for infections. The SPSS statistical software package (version 17.0; SPSS Inc., Chicago, USA) and GraphPad Prism 8.0.1 were used for analyses. A $p<0.05$ was considered statistically significant.

\section{Declarations}

\section{Ethical approval}

The study was carried out in accordance with The Code of Ethics of the World Medical Association (Declaration of Helsinki) standards and the Argentinian legislation for protection of personal data (Law 25326). The experimental protocol was approved by the Institutional Ethics Committee from the Hospital 
Nacional de Clinicas, Universidad Nacional de Cordoba (RePIS \#3512). All patients provided a signed written informed consent form agreeing to share their own anonymous information prior to enrollment.

\section{Authors' contributions}

R.D.M., G.M., and R.M. participated in the conception and design of the study. G.M., D.A.P., A.D.T., C.O. and R.I.M. participated in the acquisition, analysis and interpretation of data. R.D.M. wrote the manuscript text and D.A.P. prepared the figure and tables. All authors critically reviewed the manuscript and approved the final version before submission.

\section{Additional Information}

Competing interests

The authors declare no competing interests.

\section{References}

1. Gimenes, F. et al. Male infertility: a public health issue caused by sexually transmitted pathogens. Nat Rev Urol. 11, 672-687 https://doi.org/10.1038/nrurol.2014.285 (2014).

2. Vander Borght, M. \& Wyns, C. Fertility and infertility: Definition and epidemiology. Clin Biochem. 62, 2-10 https://doi.org/10.1016/j.clinbiochem.2018.03.012 (2018).

3. Hart, R. J. Physiological Aspects of Female Fertility: Role of the Environment, Modern Lifestyle, and Genetics. Physiol Rev. 96, 873-909 https://doi.org/10.1152/physrev.00023.2015 (2016).

4. Schjenken, J. E. \& Robertson, S. A. The Female Response to Seminal Fluid. Physiol Rev. 100, 1077-1117 https://doi.org/10.1152/physrev.00013.2018 (2020).

5. Tang, W. et al. Pregnancy and fertility-related adverse outcomes associated with Chlamydia trachomatis infection: a global systematic review and metaanalysis. Sex Transm Infect. https://doi.org/10.1136/sextrans-2019-053999 (2019).

6. Brunham, R. C. \& Rappuoli, R. Chlamydia trachomatis control requires a vaccine. Vaccine. 31, 1892-1897 https://doi.org/10.1016/j.vaccine.2013.01.024 (2013).

7. Paavonen, J. Chlamydia trachomatis infections of the female genital tract: state of the art. Ann Med. 44, 18-28 https://doi.org/10.3109/07853890.2010.546365 (2012).

8. Mackern-Oberti, J. P. et al. Chlamydia trachomatis infection of the male genital tract: an update. J Reprod Immunol. 100, 37-53 https://doi.org/10.1016/j.jri.2013.05.002 (2013).

9. Farsimadan, M. \& Motamedifar, M. Bacterial infection of the male reproductive system causing infertility. J Reprod Immunol. 142, 103183 https://doi.org/10.1016/j.jri.2020.103183 (2020).

10. Stojanov, M., Baud, D., Greub, G. \& Vulliemoz, N. Male infertility: the intracellular bacterial hypothesis. New Microbes New Infect. 26, 37-41 https://doi.org/10.1016/j.nmni.2018.08.012 (2018).

11. Taylor-Robinson, D. \& Jensen, J. S. Mycoplasma genitalium: from Chrysalis to multicolored butterfly. Clin Microbiol Rev. 24, 498-514 https://doi.org/10.1128/CMR.00006-11 (2011).

12. Capoccia, R., Greub, G. \& Baud, D. Ureaplasma urealyticum, Mycoplasma hominis and adverse pregnancy outcomes. Curr Opin Infect Dis. 26, 231-240 https://doi.org/10.1097/QC0.0b013e328360db58 (2013).

13. Volgmann, T., Ohlinger, R. \& Panzig, B. Ureaplasma urealyticum-harmless commensal or underestimated enemy of human reproduction? A review. Arch Gynecol Obstet. 273, 133-139 https://doi.org/10.1007/s00404-005-0030-1 (2005).

14. Keane, F. E., Thomas, B. J., Gilroy, C. B., Renton, A. \& Taylor-Robinson, D. The association of Mycoplasma hominis, Ureaplasma urealyticum and Mycoplasma genitalium with bacterial vaginosis: observations on heterosexual women and their male partners. Int J STD AIDS. 11, 356-360 https://doi.org/10.1258/0956462001916056 (2000).

15. Manhart, L. E., Holmes, K. K., Hughes, J. P., Houston, L. S. \& Totten, P. A. Mycoplasma genitalium among young adults in the United States: an emerging sexually transmitted infection. Am J Public Health. 97, 1118-1125 https://doi.org/10.2105/AJPH.2005.074062 (2007).

16. Huang, C. et al. Ureaplasma urealyticum and Mycoplasma hominis infections and semen quality in 19,098 infertile men in China. World J Urol. 34, 10391044 https://doi.org/10.1007/s00345-015-1724-z (2016).

17. Ahmadi, M. H., Mirsalehian, A., Sadighi Gilani, M. A., Bahador, A. \& Talebi, M. Asymptomatic Infection With Mycoplasma hominis Negatively Affects Semen Parameters and Leads to Male Infertility as Confirmed by Improved Semen Parameters After Antibiotic Treatment. Urology. 100, 97-102 https://doi.org/10.1016/j.urology.2016.11.018 (2017).

18. Taylor-Robinson, D., Jensen, J. S., Svenstrup, H. \& Stacey, C. M. Difficulties experienced in defining the microbial cause of pelvic inflammatory disease. Int J STD AIDS. 23, 18-24 https://doi.org/10.1258/ijsa.2011.011066 (2012).

19. Taylor-Robinson, D. Infections due to species of Mycoplasma and Ureaplasma: an update. Clin Infect Dis. 23, 671-682 quiz $683-674$ https://doi.org/10.1093/clinids/23.4.671 (1996).

20. Kwak, D. W., Hwang, H. S., Kwon, J. Y., Park, Y. W. \& Kim, Y. H. Co-infection with vaginal Ureaplasma urealyticum and Mycoplasma hominis increases adverse pregnancy outcomes in patients with preterm labor or preterm premature rupture of membranes. J Matern Fetal Neonatal Med. 27, 333-337 
https://doi.org/10.3109/14767058.2013.818124 (2014).

21. Farahani, L. et al. The semen microbiome and its impact on sperm function and male fertility: A systematic review and meta-analysis. Andrology. https://doi.org/10.1111/andr.12886 (2020).

22. Kroon, S. J., Ravel, J. \& Huston, W. M. Cervicovaginal microbiota, women's health, and reproductive outcomes. Fertil Steril. 110, $327-336$ https://doi.org/10.1016/j.fertnstert.2018.06.036 (2018).

23. Tsevat, D. G., Wiesenfeld, H. C., Parks, C. \& Peipert, J. F. Sexually transmitted diseases and infertility. Am J Obstet Gynecol. 216, 1-9 https://doi.org/10.1016/j.ajog.2016.08.008 (2017).

24. Redgrove, K. A. \& McLaughlin, E. A. The Role of the Immune Response in Chlamydia trachomatis Infection of the Male Genital Tract: A Double-Edged Sword. Front Immunol. 5, 534 https://doi.org/10.3389/fimmu.2014.00534 (2014).

25. Tang, W. et al. Pregnancy and fertility-related adverse outcomes associated with Chlamydia trachomatis infection: a global systematic review and metaanalysis. Sex Transm Infect. 96, 322-329 https://doi.org/10.1136/sextrans-2019-053999 (2020).

26. Aung, E. T. et al. International travel as risk factor for Chlamydia trachomatis infections among young heterosexuals attending a sexual health clinic in Melbourne, Australia, 2007 to 2017. Euro Surveill. 24, https://doi.org/10.2807/1560-7917.ES.2019.24.44.1900219 (2019).

27. CDC. Sexually Transmitted Disease Surveillance 2018.. (2019).

28. Chen, H. et al. Chlamydia trachomatis and Human Papillomavirus Infection in Women From Southern Hunan Province in China: A Large Observational Study. Front Microbiol. 11, 827 https://doi.org/10.3389/fmicb.2020.00827 (2020).

29. Piscopo, R. C. et al. Increased prevalence of endocervical Mycoplasma and Ureaplasma colonization in infertile women with tubal factor. JBRA Assist Reprod. 24, 152-157 https://doi.org/10.5935/1518-0557.20190078 (2020).

30. Abusarah, E. A., Awwad, Z. M., Charvalos, E. \& Shehabi, A. A. Molecular detection of potential sexually transmitted pathogens in semen and urine specimens of infertile and fertile males. Diagn Microbiol Infect Dis. 77, 283-286 https://doi.org/10.1016/j.diagmicrobio.2013.05.018 (2013).

31. Sleha, R. et al. Prevalence of Mycoplasma hominis and Ureaplasma urealyticum in women undergoing an initial infertility evaluation.Epidemiol Mikrobiol Imuno/65,232-237.

32. Gdoura, R. et al. Assessment of Chlamydia trachomatis, Ureaplasma urealyticum, Ureaplasma parvum, Mycoplasma hominis, and Mycoplasma genitalium in semen and first void urine specimens of asymptomatic male partners of infertile couples. J Androl. 29, 198-206 https://doi.org/10.2164/jandrol.107.003566 (2008).

33. Song, T., Liu, Z., Zhang, Y., Han, Y. \& Huang, J. Detection of Ureaplasma spp. serovars in genital tract of infertile males. J Clin Lab Anal. 33 , e22865 https://doi.org/10.1002/jcla.22865 (2019).

34. Moretti, E. et al. The presence of bacteria species in semen and sperm quality. J Assist Reprod Genet. 26, 47-56 https://doi.org/10.1007/s10815-0089283-5 (2009).

35. Boeri, L. et al. Semen infections in men with primary infertility in the real-life setting. Fertil Steril. 113, 1174-1182 https://doi.org/10.1016/j.fertnstert.2020.01.034 (2020).

36. Moridi, K. et al. Epidemiology of genital infections caused by Mycoplasma hominis, M. genitalium and Ureaplasma urealyticum in Iran; a systematic review and meta-analysis study (2000-2019). BMC Public Health. 20, 1020 https://doi.org/10.1186/s12889-020-08962-5 (2020).

37. Imudia, A. N., Detti, L., Puscheck, E. E., Yelian, F. D. \& Diamond, M. P. The prevalence of ureaplasma urealyticum, mycoplasma hominis, chlamydia trachomatis and neisseria gonorrhoeae infections, and the rubella status of patients undergoing an initial infertility evaluation. J Assist Reprod Genet. 25, 43-46 https://doi.org/10.1007/s10815-007-9192-z (2008).

38. Lee, J. Y. \& Yang, J. S. Prevalence and Antimicrobial Susceptibility of Mycoplasma hominis and Ureaplasma Species in Nonpregnant Female Patients in South Korea Indicate an Increasing Trend of Pristinamycin-Resistant Isolates. Antimicrob Agents Chemother. 64, https://doi.org/10.1128/AAC.01065-20 (2020).

39. Lee, M. Y., Kim, M. H., Lee, W. I., Kang, S. Y. \& Jeon, Y. L. Prevalence and Antibiotic Susceptibility of Mycoplasma hominis and Ureaplasma urealyticum in Pregnant Women. Yonsei Med J. 57, 1271-1275 https://doi.org/10.3349/ymj.2016.57.5.1271 (2016).

40. Buzo, B. F. et al. Association between Mycoplasma and Ureaplasma airway positivity, ammonia levels, and outcomes post-lung transplantation: A prospective surveillance study. Am J Transplant. https://doi.org/10.1111/ajt.16394 (2020).

41. Zegers-Hochschild, F. et al. International Committee for Monitoring Assisted Reproductive Technology (ICMART) and the World Health Organization (WHO) revised glossary of ART terminology, 2009. Fertil Steril 92, 1520-1524, doi:10.1016/j.fertnstert.2009.09.009 (2009).

\section{Figures}


a

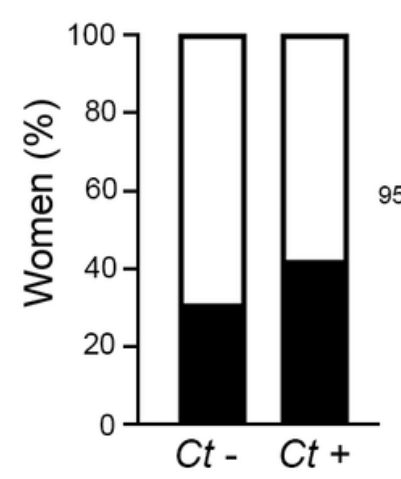

d

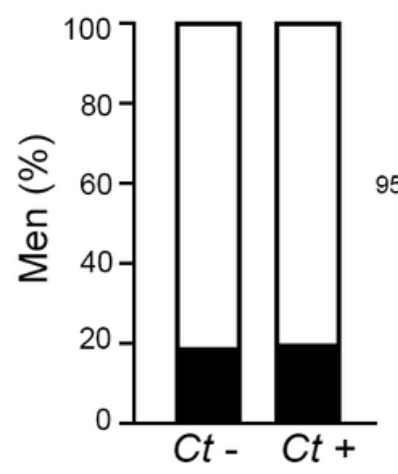

b
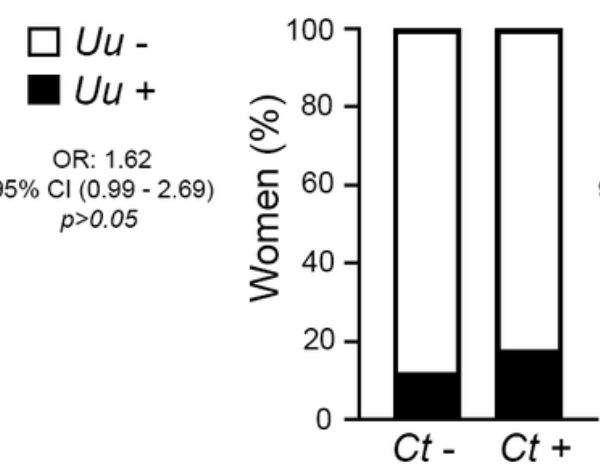

e

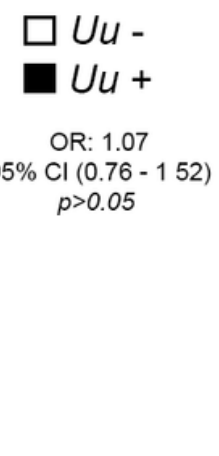

e

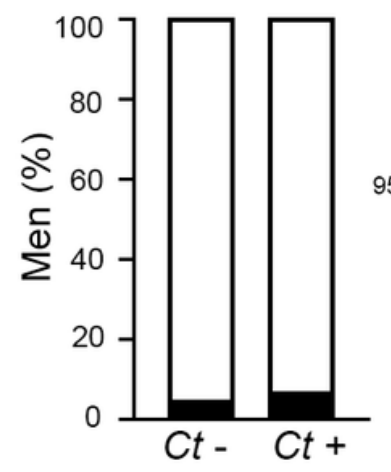

C
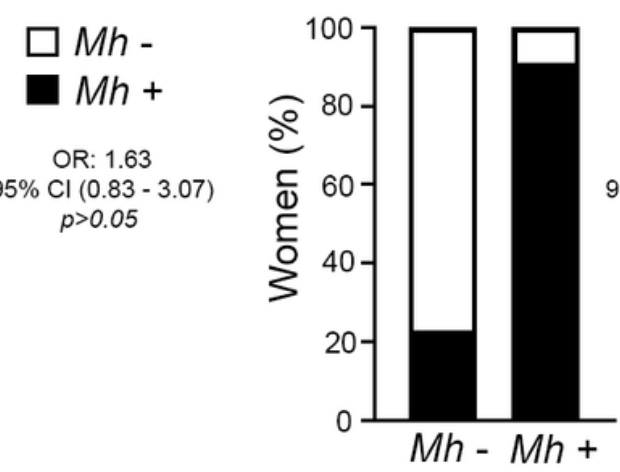

$\square \cup u-$

- Uu+

OR: 33.84

$95 \% \mathrm{Cl}(20.25-56.86)$

$p<0.0001^{*}$

f
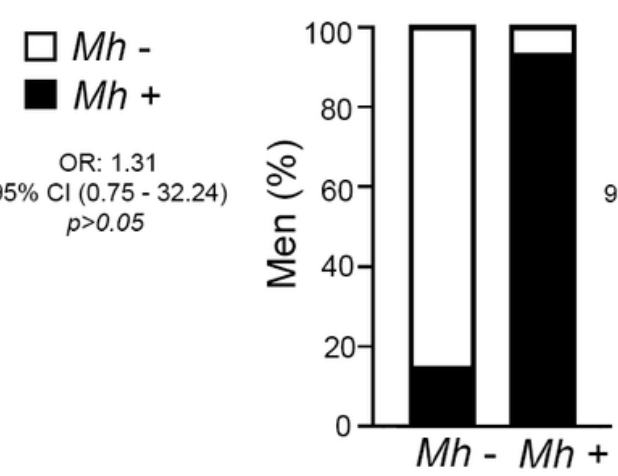

Uu -

$\mathrm{Uu}+$

OR: 71.83

$95 \% \mathrm{Cl}(41.89-187.10)$

$p<0.0001^{*}$

Figure 1

C. trachomatis (Ct), U. urealyticum ( $\mathrm{Uu}$ ) and $\mathrm{M}$. hominis ( $\mathrm{Mh}$ ) co-infections/colonizations in infertile patients. Frequency of positive Uu infection/colonization in Ct-infected (Ct+) or Ct-non infected (Ct-) women (a) or men (d). Frequency of positive Mh infection/colonization in Ct-infected (Ct+) or Ct-non infected (Ct-) women (b) or men (e). Frequency of positive Uu infection/colonization in Mh-infected/colonized (Mh+) or Mh-non infected/colonized (Mh-) women (c) or men (f). Data are shown as frequency. Chi square test were assessed and odds ratio with $95 \%$ confident interval $(\mathrm{OR}, 95 \% \mathrm{Cl})$ calculated. $\mathrm{A}$ * $\mathrm{p}<0.05$ was considered statistically significant.

\section{Supplementary Files}

This is a list of supplementary files associated with this preprint. Click to download.

- Supplementaryinformation.pdf 